\title{
Responding to the Paris Climate Agreement: global climate change mitigation efforts
}

\author{
(C) Higher Education Press and Springer-Verlag GmbH Germany, part of Springer Nature 2018
}

Since the Paris Climate Agreement was adopted by consensus in December 2015, the global society has made various efforts to respond to this Agreement. The essential element of the Paris Climate Agreement is the so-called Nationally Determined Contributions (NDCs), specifying the long-term greenhouse gas (GHG) reduction targets beyond 2020. Unlike the different legal obligations of developed and developing countries specified in the precedent Kyoto Protocol, the NDCs under the Paris Climate Agreement apply equally to all countries. All the signed countries were asked to submit their Intended Nationally Determined Contributions (INDCs) before the 2015 Paris Climate Summit, which serve, unless otherwise provided, as the initial NDCs after the ratification of the Agreement. However, there is no mechanism to force a country to set a specific target by a specific date, but each target should go beyond previously set targets. Another challenge is that in June

Received Jul. 26, 2018; online Aug. 26, 2018

Yong GENG ( $₫)$

School of Environmental Science and Engineering, Shanghai Jiao Tong University, Shanghai 200240, China; China Institute for Urban Governance, Shanghai Jiao Tong University, Shanghai 200030, China; Shanghai Institute of Pollution Control and Ecological Security, Shanghai 200092, China

E-mail: ygeng@sjtu.edu.cn

Tsuyoshi FUJITA

National Institute for Environmental Studies, Tsukuba, Ibaraki 3058506, Japan

Anthony CHIU

Gokongwei College of Engineering, De La Salle University, Manila 1004, the Philippines

Hancheng DAI

College of Environmental Sciences and Engineering, Peking University, Beijing 100871, China

Han HAO

State Key Laboratory of Automotive Safety and Energy, Tsinghua University, Beijing 100084, China
2017, US President Donald Trump announced his intention to withdraw the US from the Agreement. Under the Agreement, the earliest effective date of withdrawal for the US is November 2020, shortly before the end of President Trump's current term. The US was responsible for $15.5 \%$ of global $\mathrm{CO}_{2}$ emissions from fuel combustion in 2015 [1]. The US's withdrawal has brought a great uncertainty to the implementation of the Paris Climate Agreement and induced a lot of global disputes.

Nevertheless, many national governments have initiated their great efforts in reducing GHG emissions. The promoted strategies include but are not limited to deploying energy-efficient technologies, promoting the use of low-carbon fuels, optimizing grid mix, incorporating carbon trade mechanism, developing low-carbon supply chain, advocating low-carbon lifestyles, etc [2]. These efforts are critical in preventing an unconstrained growth of GHG emissions. Taking China as an example, the $\mathrm{CO}_{2}$ intensity in 2014 was decreased by $34 \%$ from the 2005 level [3]. In addition, EU achieved an $18.4 \%$ net reduction of $\mathrm{CO}_{2}$ emissions from fuel combustion during 2005-2015 [1].

However, there is a lack of integrated and systemic synergy of existing mitigation policies to meet the overall mitigation target. It is unclear whether existing policy instruments are effective enough to achieve the climate target, and if not, how much further efforts are needed; what the co-benefits, risks and spillovers of individual policies are, and how the diversified policies can be combined in an effective way. Besides, there is also a lack in the synergy between climate policies and other socio-economic policies, such as energy security, air pollutions. Most policies are designed with a narrow focus on solving the target issue, while ignoring cobenefits on wider dimensions [4,5]. Such narrowlyfocused policies are inherently inefficient due to the miscounting of social costs and benefits, and lead to the discount of the overall effect. 
The Paris Climate Agreement, with the binding NDCs targets as the major constraints, calls for a targetoriented mitigation policy framework. Preliminary researches have been conducted with efforts to reconcile the top-down targets with the bottom-up strategies $[6,7]$. Such studies are extremely important in informing the government how the national overall mitigation targets can be achieved at the regional and sectoral levels; what strategies are needed to guarantee the realization of the NDCs targets; how these strategies can be framed in a synergized way. In this regard, the research community has played a critical role in building up a solid foundation for target-oriented mitigation strategies. This special issue reflects the most recent research efforts from different countries. Under the guidance of Professor Xiangwan Du, the former vice president of Chinese Academy of Engineering, we developed this editorial. In total, there are 12 papers collected in this special issue, which focus on different perspectives on responding to the Paris Climate Agreement.

Key contributions to this special issue:

1. Du reviewed the strategies for promoting China's low-carbon development through an energy revolution. Five essential strategies for energy revolution were proposed, including prioritizing energy saving and improving energy efficiency, phasing out coal consumption, developing high-quality non-fossil fuel energy, stabilizing oil consumption and increasing gas consumption, developing smart energy network. Lowcarbon development is the only way to avoid falling into the middle income trap. China should find a new pathway toward sustainable development, which can coordinate economic development with low-carbon transition simultaneously.

2. Mulcahy and Mulcahy reviewed the key scientific statements and facts presented to the participants before the COP21 conference in 2015. The authors argue about how diplomacy brought about the success of the conference, with 195 countries coming to the agreement that climate change is a real and present danger. The effectiveness of possible major mitigation programs was evaluated, and literature review on current progress was also conducted. The results show that under the business-as-usual scenario, there is a $99 \%$ chance that 0.66 trillion USD worth of global financial assets will be lost due to climate change. Using mitigating actions to limit warming to $2^{\circ} \mathrm{C}$, the losses can be reduced by a half.

3. He reviewed China's climate change mitigation experiences in the post-Paris Climate Agreement era. Policies for promoting energy and economy low-carbon transition were discussed from the perspectives of energy consumption revolution, energy supply revolution, and institutional and technological innovation support. In addition, strategies to enhance China's influence and leadership in global climate governance were then analyzed. In general, China's experiences in seeking win-win results in economic growth and $\mathrm{CO}_{2}$ emission reduction are of great value to other developing countries and should be shared globally.

4. Dai et al. assessed the impacts of the US withdrawal from Paris Agreement on China and India using the computable general equilibrium model of the global economy, particularly focusing on carbon emission space and mitigation cost. The US withdrawal would cost the world valuable time dealing with climate change, considering the important role that the US has played in the international climate negotiation and governance. By setting up eight scenarios assuming US withdraw from Paris Agreement to different extents under NDC and $2^{\circ} \mathrm{C}$ scenarios, they found that the failure of the US to honor its NDC commitment will increase its carbon emission space and decrease its mitigation cost. However, the carbon emission space of China and India will be reduced, and their mitigation costs will be raised substantially. Nevertheless, the vacuum left by the US is also a good opportunity for China and India to enhance their soft power to play a more active role in leading global climate governance, through achieving the high ends of their NDC commitment and rebuilding a shared leadership with other main countries.

5. Chandran et al. outlined how the challenges for effective monitoring, reporting, and verification (MRV) can be overcome through a technological and policy innovation process. They proposed that scientists and technologists (collectively referred as expert networks) should work together with local governments and national policy makers in designing, developing, and implementing an MRV system that meets the local, national and global requirements, based on a case study in Bogor City, Indonesia. They also found that expert networks can act as interactive knowledge generators and policy interlocutors in bridging technology with policy. Finally, their case study is detailed to show how an MRV tool can be implemented in the real world.

6. Lopez et al. uncovered the drivers to changes in carbon emissions of the transport sector in the Philippines. Globally, the transport sector contributes approximately $23 \%$ of carbon emissions. Yet, the drivers to these emissions are not yet fully understood, especially in developing countries. Their study is an effort to decompose drivers to transportation carbon emissions for a developing country by using the logarithmic mean Divisia index (LMDI) method. Their results indicate that private transport ownership grew by $8 \%$ annually in rural areas, while it was only $2 \%$ in Metro Manila. Based upon these findings, policy recommendations were made to mitigate carbon emissions in the transport sector. 
7. Sun et al. evaluated the life cycle carbon footprint of the waste management sector in China and Japan. Both direct and indirect carbon footprints were evaluated by combining the life cycle assessment with the inputoutput analysis. The results imply that after fully establishing a waste recycling system in China, resource conservation from the waste management sector will have a greater potential to contribute to energy saving and emission reduction. A waste sorting and recycling system should be built before policy implementation. Also, technological feasibility in different regions should be considered. The main policy implication from this study is that developing countries should optimize their waste management sector by adopting more advanced technologies and setting up a more mature waste collection system.

8. Dou et al. provided an urban simulation model to quantitatively evaluate long-term direct and indirect impacts of strategic urban land use management to utilize local energy systems based on building-stockbased geographical information database. They promoted an efficient cogeneration thermal energy system so that the heat pumps could connect with the local heat sources and more renewable energy could be utilized. They also proposed that a positive interaction between land use changes and energy technologies could effectively promote co-benefits. Finally, they discussed the importance of quantitative planning and assessment methods to adopt "phase changes" led by various factors and uncertainties.

9. Maki et al. conducted a disaggregated analysis of energy consumption by utilizing an energy demand prediction model for monitoring and collecting data from urban sectors in Bogor City, Indonesia. The results of clustering analysis indicate that the hourly variability and the long-term variability trend can be estimated. These findings can be used for better improving the buildings' energy efficiency.

10. Uy et al. investigated the effects of uncertain demand in a multi-period and multi-objective investment setting for a microgrid system. They formulated a mixedinteger linear programming model and used the targetoriented robust optimization (TORO) approach. This profile shows tradeoffs between risk and the net present value of the corresponding investment. Specifically, the results show that pessimistic investors would be keen to have lower NPV targets in order to allow them to invest more in storage facilities.

11. Jiang et al. argued that people's social behaviors had a great impact on energy consumption and carbon emissions. They explored the role of individual environmental behaviors in energy consumption and carbon emissions at the university campus level. To improve energy conservation and cut carbon emission radically, they proposed that professional curriculums of environ- mental protection, economic initiatives, effect management, good communications, sound infrastructures and facilities were critical.

12. Hao et al. analyzed the life cycle GHG emissions of 16 representative hydrogen utilization pathways for the transport sector. The results show that under China's current grid mix, the hydrogen produced from water electrolysis yields the highest GHG emissions. In contrast, by-product hydrogen from the chlor-alkali industry yields the lowest GHG emissions. This study highlights the importance of establishing a low-carbon hydrogen supply system via appropriate technology pathway choice. It is of high relevance to other developing countries seeking appropriate hydrogen technology roadmaps.

In general, these 12 studies complement this special issue with insights into specific important topics, which also provides important experiences that the policy makers can borrow. It is expected that the research contribution from these papers can provide valuable policy insights to decision makers so that they can prepare their systemic mitigation policies by considering their own realities.

Acknowledgement This special issue was financially supported by National Natural Science Foundation of China (Grant Nos. 71325006 and $71690241)$.

\section{References}

1. IEA. $\mathrm{CO}_{2}$ Emissions from Fuel Combustion (2017 Edition). 2017, International Energy Agency, Paris

2. Somanathan E, Sterner T, Sugiyama T, et al. National and Sub-national Policies and Institutions in Climate Change 2014: Mitigation of Climate Change. Cambridge: Cambridge University Press, 2014

3. Yu Z, Geng Y, Dai H, et al. A general equilibrium analysis on the impacts of regional and sectoral emission allowance allocation at carbon trading market. Journal of Cleaner Production, 2018, 192: 421-432

4. Geng Y, Ma Z, Xue B, et al. Co-benefit evaluation for urban public transportation sector - a case of Shenyang, China. Journal of Cleaner Production, 2013, 58: 82-91

5. Jiang P, Chen Y, Geng Y, et al. Analysis of the co-benefits of climate change mitigation and air pollution reduction in China. Journal of Cleaner Production, 2013, 58: 130-137

6. den Elzen M, Fekete H, Höhne N, et al. Greenhouse gas emissions from current and enhanced policies of China until 2030: Can emissions peak before 2030? Energy Policy, 2016, 89: 224236

7. Zheng B, Zhang Q, Borken-Kleefeld J, et al. How will greenhouse gas emissions from motor vehicles be constrained in China around 2030? Applied Energy, 2015, 156: 230-240 


\section{Biosketches of Editors:}

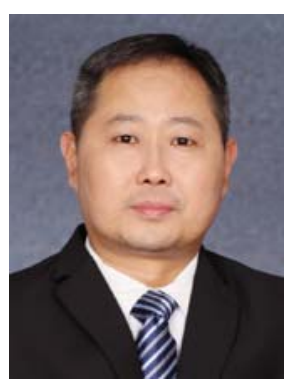

Prof. Yong Geng is Dean and a distinguished professor of School of Environmental Science and Engineering at Shanghai Jiao Tong University, Associate Dean of China Institute of Urban Governance at Shanghai Jiao Tong University. His main research field covers industrial ecology, environment management, and climate change policies. He has published over 200 peer-reviewed papers in prestigious international journals such as Science, Nature, Nature-Climate Change, Environmental Science \& Technology, etc. In 2013 he received the National Science Fund for Distinguished Young Scholars from the National Natural Science Foundation of China (NSFC) and in 2014 the title of "National hundred and thousand talents" from the Ministry of Human Resource of China. He is serving in various organizations and scientific communities, such as the Lead Author of IPCC AR-5 and IPCC AR-6, and national expert for United Nations Industrial Development Organization (UNIDO).

For more information: http://sese.sjtu.edu.cn/leaders/1486.html

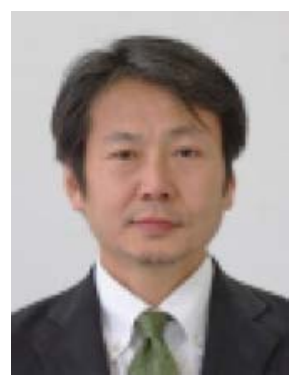

Prof. Tsuyoshi Fujita received the MCP (Master of City Planning) degree from the University of Pennsylvania in 1991 and the doctor of engineering degree from the University of Tokyo in 1997. He is the Director of the Center for Social and Environmental Systems Research, National Institute for Environmental Studies (NIES), Japan. He also serves as Appointed Professor at the Tokyo Institute of Technology in the field of applied energy, and Alliance Professor at Nagoya University in the field of environmental science. His research fields include eco-industrial development, low carbon cities, urban environment simulation systems, circular economy planning, and spatial life cycle assessment, and he has published more than 70 journal papers related to these fields to date. He is engaged in several national research projects to develop integrative urban technologies and policy simulation systems for Japanese and Asian cities and regions. Prof. Fujita is a member of Council for promotion of Future City Initiative of Cabinet Office of Japan, and he also holds a number of other academic positions including Counselor of the International Society for Industrial Ecology and Chair of the Committee on Environmental Systems, Japan Society of Civil Engineers.

For more information: http://www.nies.go.jp/researchers-e/ 201987.html

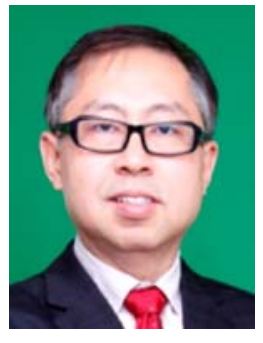

Prof. Anthony Chiu is University Fellow and professor at De La Salle University. He is a member of the United Nations International Resource Panel. Prof. Chiu has advised doctoral research works and published more than 160 papers, book chapters, and keynote documents in the field of sustainable consumption and production (SCP), resource efficient and cleaner production (RECP), and industrial ecology/eco-industrial development (EID). He is also a Philippine Permanent Delegate to the United Nations 3R Summit. He served as member of the National Pollution Adjudication Board (Pollution Court) from 2004 to 2016. He co-chairs the Industrial Engineering Certification Board. Prof. Chiu is the first Philippine awardee of the American Society of Mechanical Engineers as outstanding international correspondent, and the first Philippine ASEAN Engineer in the field of industrial engineering from academe.

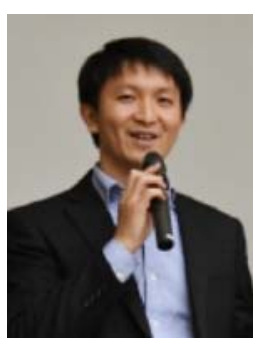

Dr. Hancheng Dai, assistant professor at College of Environmental Sciences and Engineering, Peking University, China. He received his B.S. degree from Peking University in China, M.S. degree from the Technical University of Munich in Germany and Ph.D. degree from the Tokyo Institute of Technology in Japan. Prof. Dai's research interests are in climate change economics, energy and environmental economics and policy assessment. He has been developing the state-of-the-art integrated assessment models to find out how the society could transit into a low-carbon and sustainable future at the local, national and global scales. Using these models, he explored key questions such as the mitigation cost of achieving the Copenhagen targets, Nationally Determined Contributions (NDCs) and $2{ }^{\circ} \mathrm{C}$ targets in China, the co-benefits of climate mitigation on air pollution, human health, water saving and resource efficiency, as well as the effects of emission trading policy in China. His main publications, including 6 ESI highly cited papers, are on energy economics and policy related journal.

For more information: http://scholar.pku.edu.cn/hanchengdai

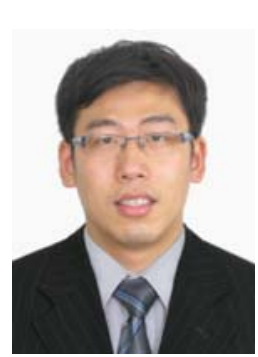

Dr. Han Hao, assistant professor at the Department of Automotive Engineering, Tsinghua University, China. He received his B.S. and Ph.D. degrees from Tsinghua University in China. Dr. Hao's research interests are lowcarbon transport and its energy, environmental, economic, resource synergies and tradeoffs. He has been developing the transport energy system model, which enables the 
estimations of the energy, environmental, economic and resource impacts from the transport sector on the national, regional and global levels. Using the model, he has explored the lithium, cobalt and nickel constraints for electric vehicles on the regional and global levels, quantified the co-benefits and risks of GHG emissions abatement by using the case of China's passenger vehicles. His main publications, including 3 ESI highly cited papers, are on energy economics and policy related journals.

For more information: https://www.researchgate.net/profile/ Han_Haol0 